\title{
O PROCESSO DE REESCRITURAÇÃO DA PALAVRA “MURO” EM TEXTOS JORNALÍSTICO DE REVISTA "VEJA"
}

\author{
THE PROCESS OF REWRITING THE WORD “MURO” IN \\ JOURNALISTIC TEXTS OF MAGAZINE "VEJA".
}

Renata Carneiro Lemes ${ }^{1}$

Taisir Mahmudo Karim ${ }^{2}$

\begin{abstract}
RESUMO
O presente artigo tem como objetivo, sob a ótica da semântica do acontecimento, analisar o processo de reescrituração da palavra muro, isto é, o modo como a referida palavra ao se repetir produz um novo significado. Para isso, a analise constituirá de quatro textos jornalísticos da revista Veja publicados nos anos 2014, 2015 e 2017, que enunciam o muro na relação com outros sentidos que rememoram um passado enunciativo, no presente do acontecimento. A base teórica e metodológica é a teoria da Semântica do acontecimento, conforme proposta por Guimarães (2002, 2004 e 2005). Assim, analisaremos o modo como o processo de reescrituração se constitui em textos jornalísticos que tematizam o "muro" enquanto acontecimento enunciativo, de modo que o locutor-jornalista, ao enunciar, é afetado por seu lugar social no acontecimento enunciativo. $\mathrm{O}$ presente artigo nos fez observar o processo de significação de outro(s) sentido(s) da palavra muro pelo efeito da repetição nos textos jornalísticos.
\end{abstract}

PALAVRAS-CHAVE: Muros; Sentidos; Textos jornalísticos; Reescrituração.

\begin{abstract}
This article aims, from the perspective of the semantics of the event, to analyze the process of rewriting the word wall, that is, the way in which the aforementioned word, when repeated, produces a new meaning. For this, the analysis will consist of four journalistic texts from Veja magazine published in 2014, 2015 and 2017, which enunciate the wall in relation to other meanings that recall an enunciative past, in the present of the event. The theoretical and methodological basis is the Semantics theory of the event, as proposed by Guimarães (2002, 2004 and 2005). Thus, we will analyze how the rewriting process is constituted in journalistic texts that thematize the "wall" as an enunciative event, so that the journalist-journalist, when enunciating, is affected by his social place in the enunciative event. This article made us observe the meaning process of another meaning(s) of the word wall by the effect of repetition in journalistic texts.
\end{abstract}

KEYWORDS: Walls; Senses; Journalistic texts; Rewriting.

\section{INTRODUÇÃO}

A temática "O processo de reescrituração da palavra "muro" nos textos jornalísticos da revista veja" diz respeito a enunciação da palavra "muro" em revistas, internet, sites de notícias, meio jornalístico e diversos outros meios de difusão de informação. As questões que insidem o processo de análise desse artigo são: como a cena enunciativa e nova temporaldiade atuam nas

\footnotetext{
${ }^{1}$ Doutoranda do Programa de pós- graduação em Linguística pela Universidade de Mato Grosso (UNEMAT), Campus Jane Vanini, Cáceres-MT, lemes.renata9@gmail.com.

2 Professor Doutor em Linguística do Departamento de Letras UNEMAT/Cáceres, coordenador do Centro de Estudo e Pesquisa em Linguagem - CEPEL, coordenador do Projeto de Pesquisa Estudo da Significação: Nomes Próprios.
} 
significações de "muro" e como os processos de reescrituração e articulação se constituem no texto jornalístico que tematiza sobre o muro? Nesse sentido, este trabalho propõe analisar, enunciativamente, o procedimento de reescrituração da palavra "muro" em textos da revista Veja, observando como esse procedimento constrói novos sentidos para a palavra.

Observa-se que a conjuntura do século XXI evoca uma textualização/atualização do muro em revistas jornalísticas. Um atual exemplo é o Projeto Político, veiculado pela mídia, do então presidente dos Estados Unidos, Donald Trump, em construir um muro entre os Estados Unidos e o México. O discurso sobre a construção do muro, na atualidade, nos permite questionar a reescrituração do muro nos diferentes recortes de textos jornalísticos da Revista Veja.

Do ponto de vista sociológico, os muros são significados como "estruturas de paredes, podendo ser de vários tipos, com a função de separar o espaço e o sujeito, seja ele amigos, vizinhos e conflitantes". (MARCHETI, 1969, p.24). No acontecimento jornalístico, o muro é significado como um "funcionamento da alusão" (GUIMARÃES, 2013, p. 17), alusão ao funcionamento da exterioridade que o constitui no texto jornalístico. Desse modo, torna-se necessário, questionar a história que permeia o muro. Segundo, Karim (2012, p. 72), a história é tratada por Guimarães como "determinante da significação, não se trata de uma história cronológica, mas sim de uma condição que na sua própria materialidade social historiciza". Depreende no excerto que a história é determinante no acontecimento enunciativo uma vez que traz ao enunciado um passado de sentidos, isto é, um memorável que ressignifica.

Nesse artigo, traçaremos um breve percurso histórico da Muralha da China e dos Muros de Berlim. Vale ressaltar que dizer sobre esses muros, numa perspectiva histórica, diz respeito ao modo como os recortes analisados, nesse artigo, tomam-os como memoráveis, pois produzem, no presente do acontecimento enunciativo, uma nova temporalidade. Em outras palavras, têm "suas marcas configuradas pelo funcionamento de linguagem que recorta e traz um passado que não é memória e nem marca temporal cronológica, mas sim rememorações de enunciações já ditas". (KARIM, 2016, p.306).

No que se refere à Muralha da China, essa não é um simples instrumento material, mas evoca um memorável, os sentidos transversos que a constitui. Isto é um movimento de sentido que diz respeito à relação de poder, de cerceamento do território e sobre a formação da identidade chinesa. De maneira que esse movimento de divisão do espaço tornou-se (cf. LOVELL, 2006) a estrutura das cidades chinesas. Durante longos períodos, a Muralha da China constituiu-se enquanto proteção ou resistência contra os Bárbaros, assim como meio de ocupar e expandir territórios estrangeiros.

Por outro lado, o Muro de Berlim tinha propósitos estritamente distintos, como o de impedimento da fuga de mão-de-obra especializada, já que a região ocidental encontrava-se com melhores condições de vida e de emprego em relação à região oriental. Os orientais, por sua vez, encontravam-se despreparados para viver sob a cultura do mercado individualista, competitivo e consumista e, consequentemente, milhares de pessoas fugiam para o ocidente, demonstrando a natureza impermeável sobre os muros. Contudo, o fato de o muro ter o sentido de proibido, assim como de morte àqueles que o transgredia, isso não assegurava-lhe a sua impermeabilidade, de modo que o muro se colocava como o lugar da falha, das transgressividades.

Nesse sentido, o muro de Berlim configurou-se como um marco na divisão de políticas, forças de interesses e ideologias contrárias. O monumento se dá a ler como o mais dramático da Guerra Fria e tem a sua carga semântica permeada por um memorável que reverbera a luta política e ideológica entre forças opositivas (socialismo e capitalismo). Desse modo, depreende-se que há um memorável que atravessa o muro e que tem a ver com a exterioridade que o constitui. Tudo isso deriva do modo de se compreender a sua não transparência na/pela história.

A revista jornalística é um veículo de linguagem, com seu meio tecnológico de escrita, de produção de diferentes discursos. Tem uma circularidade, com poder de fazer dizer diferentes temáticas que, por vezes, têm grande repercussão na sociedade. Assim, a textualidade enunciativa 
tem uma espessura semântica constitutiva de sentidos que nos permite depreender a materialidade da língua.

Mariani (1998, p. 33 -34) diz que o texto jornalístico "constrói-se com base em um pretenso domínio da referencialidade, pois baseia-se em uma concepção de linguagem que considera a língua como um instrumento de comunicação de informação". De maneira que a língua é depreendida pelo jornalismo, como um código um conjunto de signos, regras com a função de transmissão da mensagem.

A revista, entre outros meios de noticiar, tem um papel importante de interlocução, por ter a função de mediar a informação, o acontecimento de linguagem. O gesto de noticiar cria uma proximidade com a sociedade, pelo discurso, de forma que se diz produzindo um movimento político no social, produzindo sentidos. Nesse sentido, este artigo, terá dois momentos: a priori, mobilizaremos, a partir da Semântica do Acontecimento (GUIMARAES, 2004), as noções de temporalidade, reescrituração e articulação, posteriormente, procederemos às análises do procedimento de reescrituração da palavra muro em textos da revista Veja, com o propósito de observar o modo como esse procedimento constrói sentidos para a palavra.

\section{Reflexões sobre a Semântica do Acontecimento}

A semântica do acontecimento, que tem como precursor Eduardo Guimarães (2002, 2005), é uma disciplina teórica que trata a questão da significação do enunciado. Guimarães afirma que "a enunciação, enquanto acontecimento da linguagem se faz pelo funcionamento da língua" (GUIMARÃES, 2002, p.11), de modo que a enunciação é tida como um meio de fazer funcionar a língua, sem remeter o sujeito como centro da enunciação. Assim, pensa-se a enunciação sem ser afetada pela ordem do simbólico, uma vez que, como fora dito, não remete a um sujeito centralizado.

Conforme Guimarães (2005, p.68) “enunciação em um texto se relaciona com a enunciação de outros textos efetivamente realizados, alterando-os, omitindo-os, interpretando-os". Isso nos possibilita pensar que a análise de um enunciado não é feita em si mesma, mas na relação com outros enunciados, porque é assim que produz sentido, "construído pelo modo de reação de uma expressão com outras expressões do texto". (GUIMARÃES, 2005, p.28). Ademais, para Guimarães,

O espaço de enunciação é assim decisivo para se tomar a enunciação como uma prática política e não individual ou subjetiva [...]. Falar é assumir a palavra neste espaço dividido de línguas e falantes. É sempre, assim, uma obediência e/ou uma disputa [...]. Enunciar é estar na língua em funcionamento (GUIMARÃES, 2005, p. 22).

Depreende-se, pelo excerto, que a enunciação se dá em um espaço enunciativo conceitualizado como espaço de funcionamento de línguas, que se divide e se transforma por uma dispulta, espaço esse, constituído por línguas e falantes, isto é, falantes determinados pela língua; e é essencial, nesse cenário de enunciação, um enunciador que assume seu lugar produzido no enunciado. Portanto, a enunciação se dá por um acontecimento de linguagem, no funcionamento da língua. $\mathrm{O}$ acontecimento, por sua parte, é definido como "o que faz diferença na sua própria ordem” (GUIMARÃES, 2011, p. 15) e que é constituído pela temporalidade. Nessa direção, o autor afirma que,

Assim, um acontecimento não é considerado em virtude de estar num certo momento no tempo, antes de um outro acontecimento também no tempo. $\mathrm{O}$ que especifica um acontecimento é a temporalidade que ele constitui: um passado, um presente e um futuro. Ou seja, um acontecimento é diferente de 
outro porque recorta um passado de sentidos que convive com o presente da formulação do Locutor e assim traz uma projeção de futuro de sentidos que não significariam não fosse o acontecimento em questão. (GUIMARÃES, 2011, p.15).

Para o autor, a temporalização do acontecimento enunciativo recorta um passado como memorável e instala uma latência de futuro, sendo a temporalidade uma representação de um presente que abre em si uma latência de futuro, sem a qual não há acontecimento de linguagem, não há interpretação. Desse modo, todo acontecimento significa porque projeta em si mesmo um futuro. Presente e futuro são próprios do acontecimento, de modo que há um passado que significa e que é representado pelo memorável. Dito de outro modo, esta latência de futuro, que significa no acontecimento, recorta um passado como memorável.

Para Guimarães (2005, p.12) “o acontecimento é sempre uma nova temporalização, um novo espaço de conviviabilidade de tempos, sem a qual não há sentido, não há acontecimento da linguagem, não há enunciação". A afirmação do autor corrobora para compreender o sentido como algo constitutivo da linguagem, sendo a temporalização como um processo de atualização da memória que abre espaço para nova interpretação. Assim, a temporalidade do acontecimento retoma um enunciado memorável e abre em si uma latência de futuro, permitindo novas enunciações.

Ademais, Guimarães (2005, p.85), argumenta que "a enunciação tem uma determinação social e histórica que agencia lugares sociais e lugares de dizer", de modo que a cada nova enunciação, emerge um novo acontecimento e uma nova temporalização. Nesse sentido, Karim (2012 p. 70), argumenta que "A enunciação, dessa forma, ocorre no momento único de seu aparecimento, e o sentido do enunciado é uma representação, uma descrição que o enunciado traz de sua enunciação, pois para o autor é essencial". Dessa forma, a maneira como se constitui o sentido de um enunciado está relacionada ao seu funcionamento no texto, no acontecimento do dizer.

Guimarães (2012, p. 12-13), concebe o texto como "uma questão semântica e nos interessa porque significa. [...] O texto é uma unidade complexa de significação", isto é, como uma unidade complexa de significação que integra enunciados no acontecimento da enunciação. Para o referido autor, isto não significa dizer que o texto tem uma unidade de significação, mas que o texto é uma unidade da mesma forma que a palavra e o enunciado, uma vez que o texto possui sentidos e por isso significa.

Nessa direção, o texto é compreendido não como uma unidade isolada e fechada em si mesma, mas em uma relação com outros textos, outros enunciados. Em outras palavras, pela perspectiva da Semântica do acontecimento, o texto constitui-se como uma unidade de sentido composta por enunciados. Nesse sentido, nesse artigo, pensar o modo como o texto jornalístico reescreve a palavra muro na relação com outros textos jornalísticos.

Para Guimarães (2007, p.87), “o processo de reescrituração liga pontos de um mesmo texto ou de outros textos". A partir do que conceitua, compreendemos que o texto não é tomado somente em si mesmo, mas na relação com outros textos, com outros enunciados e isto faz com que signifique diferentemente, pensar a linguagem fora de uma relação, pois é nessa relação com outros textos que se dá a historicidade da língua. Desse modo, "reescrever não significa dizer o mesmo, mas apontar a diferenciação do sentido" (GUIMARÃES, 2007, p. 87). O que faz com que um mesmo texto possa significar de diferentes maneiras.

A reescrituração funciona como um "procedimento pelo qual a enunciação de um texto rediz insistentemente o que já foi dito, fazendo interpretar uma forma diferente de si" (GUIMARÃES, 2005, p.17), isto é, a reescrituração é um processo que atribui algo ao reescriturado. Portanto, para a semântica do acontecimento, reescriturar é uma forma de redizer algo que já fora dito, produzindo, assim, uma deriva de sentido, uma vez que ao dizer de novo, não significa dizer 
a mesma coisa, mas produzir sentidos. É a possibilidade de um elemento do texto se reportar o outro e isto ocorre porque esses elementos não são iguais e nem transparentes entre si. Esse procedimento faz com que emerja o real da língua, a sua incompletude na relação com o histórico.

Antes de nos determos nos recortes analisados, é importante pontuarmos que tomar o texto jornalístico enquanto procedimento de reescrituração significa compreendermos a sua relação com a história, com o memorável no acontecimento enunciativo, uma vez que os recortes dos textos jornalísticos analisados são constituídos como espaços enunciativos em que os locutoresjornalísticos são atribuídos em seus direitos e aos seus modos de dizer.

\section{Os processos de reescrituração nos textos jornalísticos}

As análises serão constituídas por diferentes recortes de revistas "Veja" que enunciam a palavra "muro" em distintos anos de publicações, a cena enunciativa é construída por um Locutor (com letra maiúscula) que, ao enunciar, diz de um lugar social de locutor-jornalista, cujo dizer rememora "o muro" a partir do presente do acontecimento da reportagem. Dada essa configuração, ao considerar a Semântica do acontecimento, o "locutor é entendido como Locutorjornalísta, nos enunciados analisados, não é tido como pessoa na atividade físico-fisiólogica, ou psíquica, de falar, mas enquanto "sujeitos da língua enquanto constituídos por este espaço de línguas e falantes que chamo espaço de enunciação" (GUIMARÃES, 2002, p. 18), isto é, falantes determinados pela língua.

Depreende-se que, nos enunciados, ao repetir a palavra "muro" pelo processo de reescrituração, vai se construindo uma relação com o acontecimento do dizer que recorta um memorável no presente do acontecimento. Assim, em cada recorte o muro vai sendo materializado de forma diferente. Os procedimentos se dão pelo processo de reescrituração e articulação em cada enunciado. Compreendemos, desse modo, que o muro, no texto, funciona como uma marca enunciativa que faz funcionar o equívoco, a partir da qual esse efeito desestabiliza o sentido sociológico da palavra.

R1: Os muros e cercas de fronteira já feitos ou em construção no mundo poderiam dar uma volta e meia em torno do Brasil. Eles aliviam a insegurança das populações, mas não são impermeáveis aos imigrantes. A globalização é celebrada por eliminar fronteiras políticas e econômicas e por aproximar culturas de diferentes partes do mundo. Após a década de 90, contudo, começou a sofrer um efeito reverso: a multiplicação de muros em fronteiras nacionais. Um terço dos países já ergueu ou está edificando quase 400 quilômetros de muros ou cerca em torno e seu território, uma extensão quatro vezes superior à registrada em 1989, quando foi derrubado o muro de Berlim e suficiente para dar uma volta no Brasil. A conta feita pela geográfica Elisabeth Vallet, da universidade de Quebec, no Canadá, inclui 19.600 quilômetros já finalizados e outros 20.200 em obras. (Veja, 2 setembro de 2015. p.68-70, grifo nosso).

No recorte "Eles aliviam a insegurança das populações, mas não são impermeáveis aos imigrantes", ocorre um exemplo de reescrituração da palavra "muros" por condensação mediante a utilização do pronome anafórico "eles", conjugado na terceira pessoa do plural; elemento enunciativo que reescritura o termo "muros". Por outro lado, pelo funcionamento do elemento sequencial "mas", que reescreve por condensação um jogo enunciativo entre os muros permeáveis e os muros impermeáveis, levando em consideração a sua falha, a sua equivocidade no modo de significar no social, isto é, o muro é reescriturado pela conjunção "mas" como o lugar da transgressividade, da ineficácia no modo de impedir o tráfego. O operador argumentativo "mas", no enunciado, faz significar a palavra muro numa relação com a antítese, com o argumento 
contraditório, entre proibir de um lado e de transgredir de outro. Nesse caso, conforme Guimarães (2009, p. 52), temos "um marcador de uma operação argumentativa (enunciativa do Locutor). Continuando, diz o autor (Idem), "podemos ver que o mas incide sobre a dupla de enunciados coordenados" (Grifo nosso).

Chama-se atenção para o enunciado "A globalização é celebrada por eliminar fronteiras políticas e econômicas e por aproximar culturas de diferentes partes do mundo", há um procedimento de reescrituração por definição, em que estabelece, no caso, sentido ao definir o termo anterior. A globalização é definida como a eliminação de fronteiras políticas e econômicas, e também por aproximação das culturas de diferentes partes do mundo.

No recorte "Após a década de 90, contudo, começou a sofrer um efeito reverso: a multiplicação de muros em fronteiras nacionais" remete ao prodecimento reescrituração apositiva ao explicar o termo antecedente, o seu pressuposto. Conforme Guimarães (2012, p. 2),"a reescrituração apositiva se apresenta enunciativamente de modo distinto do elemento reescriturado. Poderíamos dizer que a reescrituração apositiva aparece em algo dito como pressuposto, diferentemente do reescriturado". Desse modo, essa relação apositiva se dá porque enunciado "a multiplicação de muros em fronteiras nacionais" predica/explica o termo anterior "Após a década de 90, contudo, começou a sofrer um efeito reverso:".

O recorte "uma extensão quatro vezes superior à registrada em 1989, quando foi derrubado o muro de Berlim e suficiente para dar uma volta no Brasil", reescreve por substituição a palavra estabelecendo movimentos de idas e vindas, tendo como ponto de partida um acontecimento localizado no passado, como no caso do Muro de Berlim configurado, sócio historicamente, como um marco na divisão política e ideológica entre o socialismo e capitalismo. O muro, nesse recorte, é reescriturado pelo processo sócio-histórico ideológico do Muro de Berlim que se diz produzindo sentido de segregação no acontecimento da enunciação. E isso faz pensar o modo como a língua constrói o sentido e que este não está na literalidade das palavras, isto é, não se detém a opacidade da materialidade, mas advém de uma memória produzida anteriormente, pelos sentidos transversos, como já ditos, "é como se o passado nevasse sobre nós". (ROBIM, 2016, p.26). Ou seja, um retorno.

Observa-se, no enunciado “Após, a década de 90, contudo, começou a sofrer um efeito reverso: a multiplicação de muros em fronteiras nacionais. Um terço dos países já ergueu ou está edificando quase 400 quilômetros de muros ou cerca em torno e seu território, uma extensão quatro vezes superior à registrada em 1989, quando foi derrubado o muro de Berlim e suficiente para dar uma volta no Brasil." que o muro, constitui-se pela reescrituração como um processo memorável do muro de Berlim, uma atualização, de um acontecimento enunciativo. É a partir do acontecimento enunciativo que a reescrituração, a relação com o outro enunciado ganha notoriedade, em outras palavras, "liga pontos de um mesmo texto ou de outros textos" (GUIMARÃES, 2007, p.87), uma vez o enunciado "após a década de 90 o muro em fronteiras nacionais" liga pelo processo da atualização da memória ao "muro de Berlim. Assim, observa-se que a relação entre enunciados que integram um mesmo texto é determinada pelo modo como cada um inscreve-se na memória do dizível sobre o muro, e como essa operação atravessa e constitui o texto.

O processo de reescrituração da palavra muro, nos enunciados, fez que, ao retomar alguma expressão, algo signifique de outro modo, em outras palavras, o modo como a palavra muro é reescriturada por cercas, muros de Berlim, fronteira, barreiras entre outros sentidos, isto é, a medida que a palavra muro é dita novamente produz produzir novos sentidos. Portanto, o procedimento semântico de reescritura faz com que algo do texto seja interpretado de maneira diferente. Para Guimarães (2007, p.87), "reescrever não significa "dizer" o mesmo, mas apontar a diferenciação de sentido"entre uma determinada forma e a sua reescritura. Nesse sentido, há que se pensar a natureza deste "algo novo" que se apresenta a partir da reescrituração, além de compreender como os elementos envolvidos nesse processo significam e em que 
medida podem ser considerados como atribuindo sentidos. Desse modo, palavra o muro, nos enunciados, é tida como o lugar em que o sentido é dividido, isto é, pode ser outro, produzido pela operação de reescrituração, um percurso de significação no acontecimento enunciativo, à medida que a palavra muro deriva o sentido, vai instalando no procedimento da reescrituração e produzindo, dessa maneira, o deslizamento de sentido.

No enunciado "Os muros e cercas de fronteiras construídas já feitas ou em construção", ocorre o procedimento da articulação ao usar a conjunção coordenativa "e" para adicionar o elemento cerca. Guimarães (2009, p.51) define a articulação como "o procedimento pelo qual se estabelecem relações semânticas em virtude do modo como os elementos linguísticos, pelo agenciamento enunciativo, significam sua contiguidade". Sendo as contiguidades linguísticas compostas por elementos linguísticos, especificamente por uma relação do Locutor (falante do espaço de enunciação). A articulação é constituída por três modos diferentes, sendo esses eles, por dependência, por coordenação e por incidência, que se configuram da seguinte forma:

\begin{abstract}
Nas articulações de dependência e coordenação o acontecimento especifica uma operação pela qual o Locutor relaciona elementos do enunciado, na articulação por incidência o acontecimento especifica uma operação pela qual o Locutor relaciona sua enunciação com o enunciado. (idem).
\end{abstract}

No recorte, a articulação de coordenação se dá quando a conjunção coordenativa "e" que adiciona o elemento cerca ao enunciado. No enunciado "quase 400 quilômetros de muros ou cerca em torno e seu território"a conjunção de alternância "ou" semantiza a ideia de alternância que conforme o texto, tanto os muros e cercas de fronteiras construídas, quanto os em construção no mundo, poderiam dar uma volta e meia em torno do Brasil. $\mathrm{Na}$ expressão "Muro e cercas de fronteira" ocorre a articulação por dependência que "se dá quando os elementos contíguos se organizam por uma relação que constitui no conjunto um só elemento". (GUIMARÃES, 2009, p.51). Ou seja, essa relação se dá entre muro e cercas que se vinculam a fronteira constituindo uma única unidade. Vejamos outros exemplo desses procedimentos.

R2: Muitos muros são erguidos como uma reação natural ao avanço do comércio multilateral, à rapidez das comunicações e ao barateamento dos transportes. "A globalização criou uma sensação de insegurança em muitos indivíduos. Os muros revertem isso ao reafirmar a identidade nacional e a soberania dos países", diz a geográfica Elisabeth.[...] A ideia de fortificar fronteiras é tão antiga quanto a movimentação humana pela Terra. As primeiras divisórias físicas entre povos remontam ao século II a.c quando a Muralha da China foi concluída. (Veja, 2 setembro de 2015. p.68-70, grifo nosso).

No enunciado "Muitos muros são erguidos como uma reação natural ao avanço do comércio multilateral, à rapidez das comunicações e ao barateamento dos transportes", observa-se que há uma pluralização de distintos motivos que desencadeiam a construção dos muros em diversos países. A formulação toca nas relações de comércio, no avanço do capitalismo entre os países e assim, o muro torna-se o limite de sentidos. Há dois procedimentos no recorte o de reescrituração por substituição pela palavra "reação natural" e o de articulação por coordenação pela coordenativa "e". Ou seja, no primeiro caso o dizer sobre o muro é reescriturado por substituição, enquanto uma reação natural que dispõe de forma transparente de impedir as relações sociais, comerciais, econômicas e políticas entre países, apagando, nesse processo, o atravessamento político, histórico e ideológico pelo efeito da globalização. Já no segundo, a articulação de coordenação se dá quando a conjunção coordenativa "e" toma os elementos à rapidez das comunicações e ao barateamento dos transportes como de mesma natureza. 
No recorte "A ideia de fortificar fronteiras é tão antiga quanto a movimentação humana pela Terra", há o exemplo de reescrituração por substituição pela palavra fronteira, sendo que nesse processo de reescrituração a expressão "muro" é significado diferentemente, isto é, pela palavra fronteira. Embora, no enunciado, a fronteira e o muro interceptam o sujeito, e esse dizer é atravessado por uma história que diz respeito a movimentação humana na Terra, o procedimento de reescrituração por subsitituição da palavra muro não estabelece uma relação de uniformidade com o sentido de fronteira, mas de diferença que é constitutivo do processo de reescrituração.

Notamos, ainda, que o enunciado "A globalização criou uma sensação de insegurança em muitos indivíduos. Os muros revertem isso ao reafirmar a identidade nacional e a soberania dos países" reescritura por condensação, no qual o dêitico "isso" condensa todo o enunciado já dito, que diz sobre o efeito de insegurança causado pelo processo da globalização. A emergência de construção dos muros reverte essa sensação de efeito global e tece, pelas relações exteriores, a de insegurança à população, de modo que rompem com as relações entre países, reafirmando a identidade e a soberania. Nesse espaço simbólico, os países cerceados pelos muros investem de formas delimitadas de poder, de identidades, de valores e de leis. A soberania e a identidade produzem territórios, semanticamente, estabilizados, com seu modo distinto de identificar e significar, em sua lei, valores, cultura e leis.

Nota-se que no recorte "As primeiras divisórias físicas entre povos remontam ao século II a.c, quando a Muralha da China foi concluída", o já dito sustenta os argumentos para se construir um novo sentido para o muro, uma nova temporalidade. Em suma, uma nova interpretação é posta em cheque no acontecimento enunciativo. Desse modo, o enunciado rememora um passado de enunciação que diz sobre a Muralha da China e que significa no presente do acontecimento. $\mathrm{O}$ efeito da reescrituração faz com que um novo sentido de muro seja construído, uma vez que a exterioridade, a textualidade é efeito desse processo de reescrituração. Assim, no R2, nota-se a presença de um passado, uma memória de muro que é passível de interpretação. Um memórial de muro que diz sobre a segregação do sujeito e do espaço.

\begin{abstract}
R3: O muro de Berlim caiu simplemente porque os cidadãos que viviam presos atrás dele o derrubaram. Caiu porque não era incapaz de eliminar as razões que fazia com que os alemães-orientais quisessem escapar do regime comunista. A divisão territorial, econômica política e cultural de um mesmo povo, aliado ao fato de correr no centro da europa, na fronteira entre o leste comunista e o oeste capitalista, transformou a Alemanha em um laboratório comparativo das duas ideologias em confronto durante a Guerra fria. (Veja, 19 novembro de 2014. p.70-72, grifo nosso).
\end{abstract}

No R3, veiculado pela revista Veja, intitulado "Por que o muro caiu", a cena enunciativa o muro de Berlim constitui-se por um confronto de sentido entre o comunismo e o capitalismo. $\mathrm{O}$ que se faz necessário questionar, nesse percurso, a exterioridade dessa divisão? Observa-se que o R3 rememora um passado enunciativo sobre o muro de Berlim, no presente do acontecimento, um já dito que configura-se como ponto de partida para fundamentar uma futuridade na construtividade desse objeto de estudo no social.

Notamos que no enunciado, "o muro de Berlim caiu simplemente porque os cidadãos que viviam presos atrás dele o derrubaram. Caiu porque não era incapaz de eliminar as razões que fazia com que os alemães-orientais quisessem escapar do regime comunista. A divisão territorial, econômica política e cultural de um mesmo povo", ocorre a articulação por enumeração. Conforme Guimarães (2009, p. 58), esse procedimento "aparece só como um modo de articular os elementos de uma narrativa, adicionando, por coordenação, uma ação a outra". Nessa medida, há duas definições para a questão: por que o muro de Berlim caiu? A de que "os cidadãos que viviam presos atrás dele o derrubaram", em contra partida, a de que "não era incapaz de eliminar as razões que fazia com que os alemães-orientais quisessem escapar do regime comunista". Vale ressaltar que o 
pronome anafórico "dele" e o verbo no pretérito imperfeito "era", nos enunciados, remetem ao sujeito "muro".

Nota-se também que a expressão "porque os cidadãos que viviam presos atrás dele o derrubaram. Caiu porque não era incapaz de eliminar as razões que fazia com que os alemãesorientais quisessem escapar do regime comunista" remete ao prodecimento da reescrituração apositiva ${ }^{3}$ ao explicar o termo antecedido, o motivo que o "muro caiu". Assim essa relação apositiva se dá porque o enunciado anterior predica/explica o termo anterior.

Outro procedimento que ocorre nesse enunciado é a reescrituração por elipse, em que o sujeito O Muro de Berlim é omitido em "Caiu porque não era incapaz de eliminar as razões que fazia com que os alemães-orientais quisessem escapar do regime comunista. [...]”. Nesse caso, há omissão do sujeito no enunciado posterior ao invés de substituição ou repetição do sujeito.

No enunciado "A divisão territorial, econômica política e cultural de um mesmo povo" ocorrem dois procedimentos: o de articulação coordenada e o de reescrituração por substituição. Em que a conjunção coordenativa "e" estabelece igualdade entre os elementos de mesma natureza. Ou seja, "a articulação por coordenação se apresenta por um processo de acúmulo de elementos numa relação de contiguidade" (GUIMARÃES, 2009, p. 51), ocorre também nos enunciados “o leste comunista e o oeste capitalista" e em "política e cultural". O termo muro é também reescriturado por substituição pela expressão divisão territorial, atribuindo o sentido que se levam em considerações as questões exteriores, isto é, na cena enuciativa a muro, não é somente um espaço de delimitação, mas uma divisão territorial que agrega valores políticos, econômicos e culturais de um mesmo povo. O efeito da reescrituração, no acontecimento enunciativo, faz com que algo seja dito de outro modo, assim um novo dizer é constituído na cena enunciativa.

No enunciado "aliado ao fato de correr no centro da europa" nota-se que a expressão "fato de correr" ocorre a articulação por dependência, uma relação constituída por dois elementos que forma um só. Ou seja, essa relação se dá entre o fato que se vincula ao verbo "correr" constituindo assim, uma única unidade

R4: Ao menos o muro separando Estados Unidos do México, promessa mais emblemática de Trump, não deverá ser erguido. Apesar de $\mathrm{O}$ presidente eleito ter confirmado na coletiva de imprensa da quarta-feira 11 que a construção está de pé e que pretende enviar a conta para os mexicanos, os custos superiores a US $\$ 25$ bilhões e as dificuldades operacionais de um projeto desse porte inviabilizam a obra. Para não desagradar seus eleitores, no entanto, o empresário deve recorrer a uma barreira policial, ao invés de física, com endurecimento de leis de imigração e aumento do aparato de segurança das fronteiras. O mesmo se dá em relação à reforma de saúde do Obamacare. A promessa inicial era acabar com o projeto, mas as 20 milhões de pessoas atendidas pela medida inviabilizam sua dissolução. Trump prometeu substituir o programa, mas não explicou exatamente pelo quê. "Em relação ao muro, em relação ao Obamacare, em relação à política internacional, a retórica de Trump é sempre mais forte do que a prática", diz Ricardo Mendes, da Prospectiva. (Veja, 13.01.2017, n 2454, p.70- 73, grifo nosso).

No R4, veiculado pela revista Veja, intitulado "E agora? para onde Trump levará o mundo?", há um entrecruzamento de diferentes enunciados que permeiam sobre a construção do muro. De um lado, os Estados Unidos e suas relações sociais com outros países. De outro, o rompimento das relações sociais com o México. A questão é compreender o modo como a promessa de divisão pela estrutura física do muro mobiliza sentidos na confluência entre os Estados Unidos em relação ao México. É possível depreender, pelo R4, um jogo de interesse, de pertencimento. São relações políticas, socioeconômicos, e ideologias antagônicas. 
No enunciado "Ao menos o muro separando Estados Unidos do México, promessa mais emblemática de Trump, não deverá ser erguido". Pela base da língua, na sintaxe, observados pelo funcionamento do enunciado, os advérbios "ao menos" e "mais" embora, sintaticamente, ter o efeito de sentido de intensidade, no discurso os termos menos e mais trabalham sentidos opostos. Esse jogo discursivo nos diz sobre a não construtividade do muro, que se encontra apenas em promessas de Projetos Políticos dos Estados Unidos. O muro, no texto publicado pela revista Veja, é reescriturado por uma relação apositiva como o lugar do irrealizável e do alhures, pelo dizer, promessa mais emblemática de Trump. Nele, ecoa sentido da não-efetivação do muro, porém faz pensar o devir da projeção desse imaginário do muro. A reescrituração apositiva para Guimarães (2012, p.2) "se apresenta enunciativamente de modo distinto do elemento reescriturado", em outras palavras, a reescrituração apositiva, para o autor, atribui o sentido de um termo sobre o outro.

No enunciado "A promessa inicial era acabar com o projeto, mas as 20 milhões de pessoas atendidas pela medida inviabilizam sua dissolução", o operador argumentativo "mas", no enunciado, faz significar o projeto da construção do muro numa relação com a contradição, entre validar de um lado e o de invalidar de outro. Nesse caso, conforme Guimarães (2009, p. 52), temos "um marcador de uma operação argumentativa (enunciativa do Locutor). Continuando, diz o autor (Idem), "podemos ver que o mas incide sobre a dupla de enunciados coordenados" (Grifo nosso).

Diz, ainda, que o presidente terá que "recorrer a uma barreira policial, ao invés de física, com endurecimento de leis de imigração e aumento do aparato de segurança das fronteiras". Nesse gesto, a expressão muro é reescriturada por substituição pelas palavras barreira policial, barreira física com endurecimento de leis de imigração e aparato de segurança das fronteiras. Ou seja, a possibilidade de construção do muro tem um deslocamento para questões júridicas, as leis. De modo que o enunciado veiculado pela mídia, pelo Locutor jornalísta, tem multiplos modos de interpretar de produzir sentidos na cena enunciativa.

No enunciado "Trump prometeu substituir o programa, mas não explicou exatamente pelo quê", há a presença do operador argumentativo "mas" que produz um argumento contráditório ao enunciado anterior. O operador argumentativo "mas" no enunciado funciona como elemento da contradição, em suma da falta de explicação do enunciado anterior. Por fim, no recorte "a retórica de Trump é sempre mais forte do que a prática" ocorre o procedimento de reescrituração por definição, ao definir o termo anterior. Entende-se a reescrituração por definição por Guimarães (2007, p. 86) "como um modo de definir um termo". Assim, a retórica de Trump é definida como a mais forte do que a prática. Portanto, observa-se que nos enunciados analisados a palavra muro ao ser repetida produz uma nova significação, isto é, um movimento de retorno que atualiza um novo sentido da palavra no acontecimento enunciativo.

\section{A ilusão de um fechamento}

Ao analisarmos os processos de reescrituração, isto é, o modo como a palavra "muro" ao ser reportada no enunciado produz um novo significado, identificaram, nesse jogo enunciativo, um embate entre o mesmo e o diferente, em outras palavras, a instalação da diferença pela/na repetição do mesmo, isto é, o modo como a palavra muro ao ser reescriturada produz um significado diferente no/pelo enunciado . Essa diferença se instala pelo fato da repetição não coincidir em si mesma, mas no movimento do retorno que se presentifica.

Assim, tratamos a palavra muro no texto jornalístico como o lugar em que seu sentido divide-se em fronteira, cerca, barreira, entre outos. Esses sentidos são produzidos pela operação de reescrituração no acontecimento enunciativo. Observa-se que os enunciados rememoram os Muros de Berlim e as Muralhas da China, de maneira que os enunciados são determinados pelo modo como inscrevem na memória do dizível. Depreende-se que os recortes jornalísticos analisados sobre muro rememoraram enunciados já ditos, em distintas temporalidades. E esse passado no 
acontecimento é uma rememoração de enunciados que se dá como parte de uma nova temporalização.

Nos recortes 01, 02, 03 e 04, é pertinente dizer que a palavra muro evoca dizeres ocorridos em lugares e tempos distintos, como os dizeres sobre o Muro de Berlim e a Muralha da China, trazendo o sentido memorável da interdição contra pessoas, grupos de diferentes crenças, religiões e território distintos. Historicamente, a palavra muro, no texto, é marcada, principalmente pela memória da proteção do território. Os enunciados sobre a palavra muro na atualidade nos permitem questionar o seu sentido nos textos jornalísticos.

Desse modo, ao analisarmos o recorte enunciativo obtemos uma deriva no sentido de muro, uma vez que a palavra muro deixa marcas da produção de uma diferença, um efeito de repetição associado ao processo de rememoração do Muro de Berlim e da Muralha da China . Assim, há a necessidade, via de um esforço de lembrança, da presentificação desses outros muros no acontecimento enunciativo. Nesse espaço enunciativo, esse movimento da repetição se dá insistentemente, constituindo, assim, um memorável de outros muros.

Assim, este artigo nos permitiu compreender o muro no texto jornalístico não como uma unidade fechada, mas aberta para diferentes significações. Isto nos possibilita dizer que a análise da palavra muro não se fixa ao sentido sociológico apresentado, ao contrário ela é sempre efeito de sentido produzido na relação com sentidos que rememoram um passado enunciativo no presente do acontecimento, um já dito que desestabiliza o sentido único da palavra "muro" enquanto estrutura de parede com a função de separar o espaço e o sujeito.

\section{REFERÊNCIAS}

GUIMARÃES, Eduardo. Análise de textos: procedimentos, análises, ensino. Campinas: Editoras RG, 2011.

. Análise de texto: procedimentos, análises, ansino. São Paulo: Hucitec, $2^{a}$ ed. (2012).

. Cidade, Linguagem e tecnologia 20 anos de história. Campinas SP, Labeurb, 2013.

Domínio semântico de enunciação. In. GUIMARÃES, E. A palavra. Forma e sentido. Campinas: Pontes, 2007.

Enumeração: funcionamento enunciativo e sentido. Cadernos de estudos linguísticos, 51 (1). Campinas DL, IEL, Unicamp, 2009.

2005.

Os limites do sentido: um estudo histórico e enunciativo da linguagem. Campinas: Pontes,

História da semântica: Sujeito, sentido e gramática no Brasil. Campinas: Pontes. 2004

Semântica do acontecimento: um estudo enunciativo da designação. Campinas: Pontes, 2002.

KARIM, Taisir Mahmudo. Marcas do dizer: sentidos do Arraial do Cuyabá. ESTUDOS LINGUíSTICOS (SÃO PAULO. 1978) , v. 45, p. 305-3015, 2016.

. Dos nomes à história - o processo constitutivo de um Estado: Mato Grosso. Campinas, SP: [s.n.], 2012.

LOVEL, Julia. Grande Muralha. Tradução S. Duarte, RJ, Recorde, 2008. 
MARIANI, Bethania. O PCB e a imprensa: as conquistas no imaginário dos jornais 1922- 1989. Campinas, SP. Ed. Da Unicamp, RJ, Ed. Revan, 1998.

ROBIM, Régine. A memória Saturada. Campinas SP: Editora da Unicamp, 2016.

ROSSI, Clovís. O que é jornalismo. editora Brasiliense S.A. Coleção Primeiros Passos $1^{a}$ edição, São Paulo, 1986.

SAUSSURE, Ferdinand. Curso de Linguística Geral. Cultrix: São Paulo, 1975.

WATKINS. Nathalia. VEJA. São Paulo: Internacional, edição 1473, 2 setembro de 2015. p.68.

Submetido em 19/05/2021

Aceito em 05/07/2021 